Revista Bioética

\title{
PESQUISA
}

\section{Viver na rua: vulnerações e a bioética da proteção}

Jane da Rocha Cruz ${ }^{1}$, Stella Regina Taquette ${ }^{1}$

1. Universidade do Estado do Rio de Janeiro, Rio de Janeiro/RJ, Brasil.

\section{Resumo}

Este estudo tem como objetivo analisar como vivem pessoas em situação de rua em município de grande porte, as vulnerações que sofrem e alternativas para mudar de condição. Foi utilizado método qualitativo, mediante observação participante e entrevistas com indivíduos em situação de rua que exercem algum tipo de trabalho. A análise dos dados foi organizada em três categorias: "chegada na rua", "viver na rua" e "saída da rua". Foram entrevistados 11 homens e 2 mulheres, com entre 23 e 58 anos de idade. Os motivos que os levaram à rua se relacionam ao rompimento de vínculos familiares, consumo abusivo de drogas e desemprego. Essas pessoas vivenciam vulnerações diversas que, somadas à falta de perspectiva de emprego, dificultam a mudança de sua situação. Diante disso, este trabalho propõe que a bioética da proteção é estratégia possível de cuidado, pois oferece suporte com equidade e promove a autonomia dos indivíduos.

Palavras-chave: Pessoas em situação de rua. Vulnerabilidade social. Bioética.

\section{Resumen}

\section{Vivir en la calle: vulneraciones y la bioética de protección}

Este estudio tiene como objetivo analizar cómo viven las personas sin hogar en una gran ciudad, las vulneraciones que sufren y las alternativas para cambiar de condición. Se usó un método cualitativo, mediante la observación participante y entrevistas a personas sin hogar que desarrollan algún tipo de trabajo. El análisis de los datos se organizó en tres categorías: "llegar a la calle", "vivir en la calle" y "salir de la calle". Se entrevistó a 11 hombres y a 2 mujeres con edades entre 23 y 58 años. Las razones que los llevaron a la calle están relacionadas con la ruptura de los lazos familiares, el abuso de drogas y el desempleo. Estas personas experimentan diversas vulneraciones que, sumadas a la falta de perspectivas de empleo, les impiden salir de la situación en la que se encuentran. Ante ello, este trabajo propone que la bioética de la protección es una posible estrategia de cuidado, ya que brinda apoyo con equidad y promueve la autonomía de los individuos.

Palabras clave: Personas sin hogar. Vulnerabilidad social. Bioética.

\section{Abstract}

Living on the street: vulnerabilities and the bioethics of protection

This study sought to analyze how homeless people live in a large city, their vulnerabilities, and alternatives for leaving the streets. We used a qualitative method by participant observation and open interviews with homeless individuals who have any type of work. Data analysis was organized into three categories: "arrival on the street," "living on the street" and "leaving the street." We interviewed 11 men and two women, who were between 23 and 58 years old. The reasons that lead them to the street are related to the breaking of family bonds, drug abuse, and unemployment. They experience various vulnerabilities that, added to lack of future prospects, prevent them from leaving the street. Given this situation, the bioethics of protection is a possible care strategy as it provides support with equity and promotes individual autonomy.

Keywords: Homeless persons. Social vulnerability. Bioethics. 
Diante da pobreza e de laços familiares cada vez mais fragilizados, grande número de pessoas tem na rua a única opção de moradia. Esses indivíduos, que confrontam uma vida deixada para trás, são abandonados em sua angústia, sem perspectivas. Na rua se deparam com feridas de exclusão, discriminação, desafeto, fome, frio, violência, falta do lar. Carregam a marca da vulnerabilidade e lutam diariamente pela sobrevivência. Alguns ficam restritos a essa condição de subsistência e não desenvolvem suas potencialidades e criatividade, inerentes ao ser humano, por influência do ambiente limitador em que vivem e da condição em que se encontram. Urgente é a preservação biológica ${ }^{1}$.

No Brasil existem pessoas em situação de rua desde o período colonial, com o início do processo de libertação dos escravos e a transição para o capitalismo ${ }^{2,3}$. Contudo, somente em 2009 o Governo Federal formalizou política pública em seu favor, considerando-as grupo populacional heterogêneo que possui em comum a pobreza extrema, os vínculos familiares interrompidos ou fragilizados e a inexistência de moradia convencional regular ${ }^{4}$.

A vulnerabilidade social, entendida como riscos e adversidades que atingem indivíduos no cotidiano e em suas relações ${ }^{5}$, afeta diretamente a sobrevivência da pessoa em situação de rua. Esses sujeitos enfrentam a violência da negação do Estado e da sociedade, vivendo em condições precárias fruto de organização social injusta e desigual ${ }^{6}$. Dessa forma, têm negadas suas possibilidades de crescimento, pois o foco é unicamente subsistir.

É comum, entre pessoas em situação de rua, o uso intensivo de álcool e drogas, a incidência de transtornos psiquiátricos graves, baixa escolaridade e relações familiares fragilizadas ou rompidas $^{2}$. Ultimamente, percebe-se na rua o aumento do número de pessoas que trabalham - na maioria das vezes informalmente - e que ali permanecem por encontrar nesse espaço a possibilidade de gerar renda ou por não ter recurso financeiro para retornar a seus lares diariamente ${ }^{6}$.

A população nesta situação em cidades de grande porte é cada vez mais numerosa ${ }^{7,8}$. Pesquisa realizada em 2013 no município do Rio de Janeiro apontou 5.580 pessoas vivendo em situação de rua ${ }^{9}$. $\mathrm{O}$ que leva essas pessoas a viver ali? O que elas pensam sobre suas condições? É possível, para elas, criar espaços de singularização diante de uma sociedade limitadora e excludente? Quais são as alternativas possíveis de cuidado para ajudá-las a sair da rua e conquistar cidadania?
A bioética coloca em pauta o cuidado e a proteção dos seres vivos e de seu ambiente ${ }^{10}$. Dentre suas correntes teóricas, a bioética de proteção se apresenta como alternativa na busca de soluções para o problema da população em situação de rua, pois propõe tratar de forma desigual os desiguais $^{11-13}$. Amparada no princípio da equidade, essa vertente dá atenção diferenciada a sujeitos especialmente vulneráveis, buscando superar injustiças provenientes de desigualdades sociais. Tal abordagem analisa os saberes envolvidos na situação estudada e cumpre a função normativa de circunscrever comportamentos reprováveis e aprováveis para, por fim, ser colocada em prática na proteção da pessoa em condição de vulnerabilidade, no sentido de ampará-la e ofertar recursos para o desenvolvimento de sua autonomia ${ }^{12}$.

Nesse contexto, este estudo teve como objetivo analisar as condições de vida de pessoas em situação de rua em município de grande porte a partir de suas próprias percepções no que tange à vulnerabilidade e ao desenvolvimento de atividades laborais. Propõem-se, ao fim, alternativas de cuidado para essa população.

\section{Método}

Este estudo adotou método qualitativo, mais adequado para se obter respostas às questões estabelecidas. A pesquisa foi desenvolvida nas zonas Central e Sul do município do Rio de Janeiro/RJ, devido à grande concentração de pessoas em situação de rua nessas áreas e à movimentação econômica local, que faz circular ofertas de trabalho formal e informal ${ }^{14}$. Apesar de serem zonas com população residencial reduzida ${ }^{15}$, a circulação de pessoas favorece as perspectivas de sobrevivência da população de rua.

Contatou-se a população a ser estudada por intermédio das atividades do Consultório na Rua, realizadas por equipes de saúde multiprofissionais regulamentadas pela Política Nacional de Atenção Básica ${ }^{16}$. O programa prioriza a assistência integral à saúde em articulação inter e intrasetorial, incluindo a redução de danos e a abordagem biopsicossocial no cuidado às pessoas em situação de rua ${ }^{17,18}$. Essa população também é amparada pelo Centro de Referência Especializado de Assistência Social (Creas) ${ }^{19}$, cujas ações são voltadas às populações vulneráveis em casos de ameaças ou violação de direitos.

Uma das autoras deste estudo já havia trabaIhado com as equipes do Consultório na Rua (eCR) 
do município do Rio de Janeiro/RJ. Para iniciar o trabalho de campo, profissionais dessas equipes e do Creas Maria Lina de Castro Lima foram contatados e esclarecidos sobre o estudo, incluindo seu objeto, objetivos, metodologia e resultados esperados.

Como já destacado, a população em situação de rua é heterogênea, composta predominantemente por pessoas com distúrbios psiquiátricos e drogaditos, e ultimamente vem sendo ampliada com indivíduos que exercem alguma atividade laboral e chegam à rua devido a desestruturação familiar e desamparo social. Esta última foi a parcela da população selecionada para participar da pesquisa, devido ao interesse de analisar a situação daqueles que, mesmo afetados pelas vulnerações da rua, conseguem trabalhar.

Os critérios de inclusão abrangeram pessoas em situação de rua com 18 anos ou mais e que desenvolvem algum tipo de trabalho, formal ou informal. Foram excluídos indivíduos que fazem consumo abusivo de álcool e drogas e os que sofrem de transtorno psíquico grave, por não terem condições de serem entrevistados.

Os dados foram coletados por meio de observação participante e entrevistas abertas. A observação foi registrada em diário de campo com os seguintes dados: data, horário, local, atividade experimentada, pessoas participantes e percepções, atitudes e emoções da pesquisadora. As entrevistas seguiram roteiro com perguntas sobre os motivos que levaram os participantes à situação de rua, suas percepções sobre essa vivência, dificuldades e facilidades, desejos, como se cuidam, o que sabem fazer, se recebem alguma ajuda do poder público e, por fim, quais são suas expectativas para o futuro. Todas as entrevistas foram gravadas e transcritas na íntegra.

A análise foi baseada na leitura e releitura do diário de campo e das transcrições, visando discernir aspectos gerais e específicos de cada entrevista. Em seguida, foram feitos recortes e colagens do material para classificá-lo nas categorias preestabelecidas. Foram procuradas no texto estruturas relevantes e ideias repetidas e contraditórias, na tentativa de entender a lógica interna do grupo e o significado de suas falas. Após esta análise, buscou-se interpretar esses significados fazendo-se inferências em diálogo com a literatura.

O item "cor" não foi considerado na pesquisa, pois na literatura consultada sobre o tema a questão racial não é enfatizada, visto que sua relevância é ofuscada por outras vulnerações mais imediatas e urgentes. Além disso, na pesquisa de campo a discriminação racial não foi percebida como questão que diferenciasse as vulnerações investigadas. A população da amostra é discriminada pela condição de estar na rua, ainda que se deva reconhecer a maior vulnerabilidade da população negra, resultante do racismo estrutural.

A pesquisa foi aprovada pelo Comitê de Ética da Secretaria Municipal de Saúde do Rio de Janeiro em junho de 2017 e todas as entrevistas foram autorizadas por meio de assinatura de termo de consentimento livre e esclarecido.

\section{Resultados}

As ações das eCR do Centro da cidade do Rio de Janeiro/RJ são desenvolvidas por médicos, enfermeiros e agentes sociais. Entre essas atividades estão rodas de conversa com a população em situação de rua, consultas com a equipe técnica, promoção e prevenção de saúde e busca ativa de pacientes com doenças transmissíveis que interromperam o tratamento. No acompanhamento com o Creas Maria Lina de Castro Lima, a observação participante se deu por meio de visitas na rua com assistentes e educadores sociais que dão continuidade aos cuidados de grupo já conhecido do bairro da Urca, escutando demandas a fim de encaminhá-las ou resolvê-las. Nestes locais, a observação permitiu conhecer a dinâmica do trabalho em equipe, com distribuição de tarefas entre as pessoas em situação de rua. Também nesse momento foi possível conversar informalmente com elas e agendar as entrevistas.

Foram entrevistadas 13 pessoas, sete no Centro da cidade (todas do sexo masculino) e seis na Urca (quatro homens e duas mulheres). A maioria das entrevistas foi realizada na rua, com exceção de uma, que ocorreu em instituição pública. Os entrevistados do Centro eram assistidos pelas eCR, e os da Urca pela equipe do Creas. As entrevistas foram realizadas entre 26 de outubro de 2017 e 20 de março de 2018.

Houve dificuldades para encontrar as pessoas em situação de rua do Centro da cidade, visto que o bairro oferece diversas possibilidades de trabalhos pontuais, além do fluxo intenso de transeuntes que podem ofertar dinheiro, o que faz com que elas não permaneçam sempre no lugar que apontam como referência. Na Urca não houve obstáculos, pois os entrevistados costumavam ficar sempre no mesmo lugar. O melhor horário para as entrevistas foi no turno da tarde ou início da noite, após as atividades 
dos participantes. A única dificuldade foi o barulho das próprias pessoas em situação de rua que conversavam entre si, diminuindo a clareza das falas e por vezes interrompendo os colegas, quebrando a continuidade do pensamento.

Na descrição sociodemográfica, observa-se que $84,6 \%$ dos entrevistados são homens $(n=11)$, e a faixa etária variou de 23 a 58 anos. Quanto à escolaridade, cinco $(38,5 \%)$ entrevistados tinham completado o ensino médio, sete $(53,8 \%)$ o ensino fundamental, e somente um $(7,7 \%)$ era analfabeto. Apenas uma pessoa tinha ocupação laboral correspondente à sua formação no ensino médio (educador social). A maioria trabalhava como vendedor ambulante, e quatro $(30,8 \%)$ pessoas desenvolviam mais de uma modalidade de trabalho.

Considerando as entrevistas e as observações no campo, foram propostas três categorias a fim de sistematizar os resultados: 1) chegada na rua; 2) viver na rua; e 3) saída da rua. Os recortes das narrativas dos entrevistados estão identificados pela inicial do sexo (masculino ou feminino) e idade.

\section{Chegada na rua}

Toda causa é importante para entender a condição apresentada e buscar caminhos para alterá-la. A categoria "chegada na rua" investiga os motivos de os entrevistados estarem nessa situação, a fim de começar a delinear possibilidades de mudança. De acordo com as narrativas dos entrevistados, laços familiares fragilizados ou rompidos são a causa primeira da situação de rua. Essas relações são destroçadas por circunstâncias ou opções de vida que interferem na estrutura familiar. A dependência química costuma ser o principal fator de desequilíbrio:

"Minha ex-mulher falou na minha cara: eu nunca fui sua esposa; eu fui sua amante, porque sua esposa é essa porra branca que tu bota no nariz... (...). Aí minha vida começou a descer ladeira abaixo quando eu me separei (...). Comecei a beber, beber para esquecer, e aí perdi o meu emprego (...), perdi a confiança dos familiares e fui perdendo tudo até terminar onde eu terminei" (M50).

Os conflitos conjugais que acarretam a separação do casal são apresentados como fatores para a chegada à rua. $O$ percurso mais comum foi sair de casa e, por não ter como custear outra moradia, perambular por casas de familiares, sentindo-se como intrusos. A rua aparece então como possibilidade de conseguir mais liberdade:
"Quem ficou na rua foi eu... E em casa dos meus irmãos não vou (...). Tentei ficar no meu irmão, na minha irmã... Primeiro mês é bom, mas depois... Não é igual você estar na sua casa, você chegar, você andar até pelado..." (M49).

A quantidade de mulheres na rua é comparativamente menor. No caso delas, causa frequente da ida para a rua é a agressão. Há mulheres que, ao sofrer violência, largam tudo para conseguir se afastar do agressor. A rua é a última opção para se preservar:

"Vim para a rua por problema familiar. (...) Eu ajudei a construir a casa do meu ex-marido, e ele entrou na Maria da Penha, porque ele judiava de mim e dos meus filhos... Me espancava muito. E ia... 'Voltei, não fui preso'... Então, lá não podia viver... O lote é da minha ex-sogra" (F47).

Mas a violência doméstica, com filhos e cônjuges, não é fator apenas entre mulheres. Um entrevistado relata como a violência o levou para as ruas ainda criança:

"Eu vim para a rua com 8 anos de idade. Minha mãe começava a me bater.... Aí foi onde eu conheci a rua. Aí nas férias minha mãe me trouxe para o Rio de Janeiro contra a minha vontade... Quando a gente chegou no Rio de Janeiro, conheci meu pai, aí começaram a me bater de novo. Como eu já conhecia a rua, fiquei morando na rua e nunca mais vi ela" (M36).

A rua como lugar de liberdade, sem regras familiares, foi uma das causas apontadas para buscá-la como opção de vida:

"Um menino (...) que queria, tipo, conhecer o mundo. Ser livre. Mas jamais sabia que nele ia encontrar vários tipos de maldade... Vários tipos de droga... Quando eu ainda era bem criança, eu ainda vinha para a rua... E voltava... Mas depois que eu conheci o mundo da droga acabei ficando nesse mundo. Até hoje" (M28).

Outra causa que tem se sobressaído nos últimos anos é a perda da estabilidade financeira, devido ao desemprego e à diminuição da renda. Normalmente, trata-se de pessoas que, pela idade, têm dificuldade de se reinserir no mercado de trabalho:

"Quando eu saí do emprego, eu arrumei um trabalho na praia, pela própria idade, né? A pessoa, depois que passa dos 50 anos, é difícil você arrumar 
um emprego de carteira assinada... E aí assim eu fui conhecendo as pessoas aqui da rua, da praça, de outras praças, daí parei..." (M57).

\section{Viver na rua}

Nessa categoria, os entrevistados falaram das suas condições de vida: que vulnerações interferem no dia a dia, como se organizam, com quem contam, quais são suas escolhas subjetivas, quais são as facilidades e dificuldades de estar na rua e o quanto isso interfere na escolha do caminho a percorrer. É possível observar a falta de autonomia e de proteção a essas pessoas e como isso afeta a saída da rua.

A violência é muito presente. É comum que pertences sejam roubados por outras pessoas em situação de rua que não têm o trabalho como forma de conduzir a vida. Há, ainda, a violência do poder público, que quer retirar essas pessoas da rua à força, e a violência da sociedade civil, que não sabe lidar com a diferença e a desigualdade social:

"Foi suficiente para mim, para ser alvo de violência abusiva por autoridade policial, de violência física por pessoas que moram nos prédios onde a gente fica nas marquises. Outros tipos de violência, que não físicas, que a gente sofre no cotidiano porque a gente está na rua. Da diminuição do sujeito, do desrespeito ao sujeito. Parece que é.... Eu uso muito essa expressão: a gente é uma segunda categoria de ser humano. A gente não é da mesma categoria do ser humano que tem casa. E isso é uma experiência muito desagradável" (M37).

As variações climáticas interferem na vida das pessoas em situação de rua pela falta de proteção contra chuva, frio e vento. As marquises dos prédios são o principal abrigo, mas, ao ocupar esses espaços, os entrevistados nem sempre são bem recebidos por moradores ou proprietários dos estabelecimentos, o que gera conflitos e situações de desrespeito:

"A maior dificuldade da população de rua é quando chove... Não tem um lugar para ficar... Você se abriga na marquise.... Na Urca não existe prédio com marquise. Quando existe marquise, todas elas são gradeadas" (M56).

Segundo os entrevistados, o consumo de bebida alcoólica, especialmente a cachaça, deve-se ao preço acessível e à facilidade de compartilhá-la. A aguardente combate a fome e alivia o sofrimento psíquico, mas também impede a organização da vida. O álcool se mostra uma vulneração potente na vida dessas pessoas:

"Eu não sabia disso, mas o álcool, ele inibe apetite. E tem muita gente que bebe para matar a fome. Não é porque é alcoólatra. É porque é mais barato comprar cachaça do que comida...." (M37).

A falta de privacidade também é um problema. Estar sempre no espaço público leva as pessoas em situação de rua a ser vistas sempre de um modo que desconsidera a individualidade:

"Tudo é coletivo. As refeições são no coletivo, os quartos são no coletivo, os banheiros são no coletivo. Não existe o indivíduo" (M37).

Por sua vez, a estigmatização das pessoas em situação de rua afeta o sentimento de dignidade, prejudicando a busca de possibilidades para sair do lugar em que se encontram. A exclusão social leva à sensação de não pertencer à sociedade produtiva:

"Você vai fazer uma entrevista de emprego, um currículo, alguma coisa. Quando você dá o endereço de um abrigo, assim que você vira as costas o cara joga o teu currículo fora, porque ele automaticamente já sabe que você mora na rua. E ninguém confia em morador de rua" (M50).

A alimentação foi a facilidade mais apontada pelos entrevistados, o que leva alguns a naturalizar a situação de rua. A oferta de alimento - pelo excesso, e não pela falta - é vulneração que atinge essas pessoas, comprometendo sua autonomia e o caminho de saída das ruas:

"Facilidade é comer. Na rua o teu sofrimento são outros. Comida é fácil. Boca de rango é o que não falta" (M50).

Outro problema que vem se destacando é a exploração por meio de trabalhos informais mal remunerados. Trata-se de ocupações sem direitos trabalhistas - os famosos "bicos". Os empregadores não se responsabilizam pelos riscos da execução do serviço e remuneram com valores muito inferiores aos do mercado:

"O cara trabalha 12 horas, não tem vínculo. Se se machucar, fica por sua conta e risco. Você não tem carteira assinada, não tem vínculo trabalhista nenhum. Aí, quer dizer, os caras só lembram da 
gente quando é para esse tipo de serviço, para fazer o serviço que ninguém quer fazer "(M50).

\section{Saída da rua}

Esta última categoria diz respeito às possibilidades que os entrevistados veem para sair da situação de rua, podendo indicar caminhos para a construção de políticas públicas para essa população. Fica evidente a importância da troca de saberes e do amparo às pessoas vulneráveis, dando-lhes acesso a dispositivos de acolhimento com políticas compatíveis com a bioética da proteção ${ }^{11-13}$.

Prevaleceu na fala dos entrevistados a percepção de que o trabalho é o meio pelo qual a pessoa pode sair das ruas. A oportunidade de emprego, com regras e direitos trabalhistas garantidos é vista como possibilidade de reorganizar a vida, ainda que os participantes destaquem que essa organização não é imediata após a contratação. É preciso tempo para se adaptar à nova vida, renovar o olhar sobre si mesmo e, com responsabilidade, buscar um teto:

"Lógico que, começando a trabalhar, eu não vou sair daqui no outro dia. Eu vou ter que [usar o] primeiro mês para me organizar... Vai dar para ter mais uns mesinhos de luta ainda ai" (M49).

Para a pessoa em situação de rua, o trabalho estável e com renda adequada é a grande virada, que marca o resgate da dignidade e da cidadania:

"A partir do momento em que você começa a trabalhar, a tua vaidade já volta, já começa a se vestir melhorzinho, assim... Já sai de casa sem mochila, com a barba feita. Aí você começa a se sentir gente de novo, você começa a saber que você pode ter uma vida normal, pode ter uma namorada, pode ter uma casa, pode ter uma família, pode ter um lazer de domingo, sadio, pegar o seu filho, dar um rolé, almoçar com ele. Então o essencial para qualquer ser humano é trabalho" (M50).

Alguns relatos apontaram que as políticas públicas municipais deveriam se comprometer com ações que abrissem oportunidades de saída da rua. As unidades de reinserção social - abrigos da Secretaria Municipal de Assistência Social e Direitos Humanos - têm esse objetivo. Os entrevistados, no entanto, apontam que essas instituições precisam melhorar suas condições de acolhimento. Além disso, há críticas à localização dessas unidades, distantes dos locais onde se concentra a oferta de trabalho, em áreas de risco e longe de zonas comerciais. Os participantes também destacaram que os abrigos, como equipamentos públicos de reinserção social, deveriam oferecer capacitação profissional e firmar parcerias com instituições a fim de reintroduzir as pessoas no mercado de trabalho:

"É melhorar as condições dos abrigos. Tirar os abrigos de área de risco... Tinha que ter cursos profissionalizantes lá dentro pra quem pudesse encaminhar [ser encaminhado]. Tinha que ter uma assistência psiquiátrica boa, tinha que ter tudo isso pra você separar o joio do trigo e saber quem realmente já tá há muito tempo na rua, e se acostumou com isso, para se ressocializar" (M50).

A fala a seguir se destaca pela crítica ao caráter higienista de políticas públicas baseadas na perspectiva de que pessoas em situação de rua sujam a cidade, subtraem sua beleza e não têm utilidade ou valor para o município:

"Porque eu não vejo que existe uma política de realmente ajudar quem está na rua a sair da rua. Existe sim o interesse de sumir com essa pessoa que está na rua. Então bota ele num abrigo lá em Antares, lá em Realengo, lá na llha do Governador, que ele fica escondido" (M37).

A assistência em saúde e o acolhimento humanizados também foram apontados como formas de ajudar a pessoa a sair da rua. Ainda segundo os entrevistados, o cuidado em situações de uso abusivo de álcool e drogas e problemas de saúde mental também contribuiria para empoderar o sujeito. Ninguém consegue sair da rua sozinho. Acolher essas pessoas é fundamental para abrir novos caminhos em sua vida. Um olhar, um abraço podem fortalecer o sujeito e fazê-lo se sentir como ser humano comum. Essa atenção faz a pessoa se sentir importante para si mesma e para o outro:

"Quem está na rua precisa de cuidado. Quem está na rua precisa de casa. Primeira coisa que eu acho que uma pessoa que está na rua precisa é de um abraço. De um acolhimento real. (...) Ou por ter aderido a um programa de tratamento que, é... Me salvou a vida... Porque sozinho eu também não teria conseguido sair da rua" (M37).

Para a pessoa em situação de rua é difícil pensar no futuro, visto que o aqui e o agora são muito presentes. Quando foi pedido que falassem da perspectiva de futuro, as fisionomias revelaram leve estranhamento, como se pensassem "como 
planejar o futuro se o meu presente é incerto?" A indagação sobre desejos foi ainda mais difícil para os entrevistados. Houve alguns segundos de silêncio para responder, pois falar de desejo envolve pensar em si mesmo. Na maioria das vezes em que se propuseram essa tarefa, a dor foi intensa, minimizada apenas pela cachaça:

"Eu ainda não tenho futuro porque é tudo ainda muito incerto. Eu não sei o que vai ser de mim" (M37).

\section{Discussão}

Percebe-se no relato dos entrevistados que a principal causa para alguém ir para a rua é o rompimento ou a fragilidade dos laços familiares, no contexto de desamparo social das grandes cidades brasileiras - o que corrobora dados de outros estudos $^{1}$. A ausência de diálogo entre familiares, a falta de opções de trabalho e moradia e o uso abusivo de substâncias psicoativas - que vêm preencher um "buraco" existencial - são fatores associados. Como afirma Escorel ${ }^{1}$, a desagregação familiar depende dos limites de tolerância afetiva e da vulnerabilidade econômica que se pode suportar.

A falta de condições mínimas de sobrevivência da família - o alimento, o teto, o trabalho -, levando à miséria e à fome, gera situações de desgaste, conflitos e agressões intrafamiliares, fragilizando os vínculos existentes ${ }^{2}$. Nesse contexto, o uso de drogas e a violência desestruturam a família, levando a rupturas irreparáveis. Como resultado, a rua se torna o único caminho possível para se contar só consigo mesmo, sem incomodar o outro, na busca por liberdade ${ }^{2}$.

Segundo a literatura, o número de mulheres na rua é comparativamente menor ${ }^{6}$ - o que foi confirmado na presente pesquisa. Entre elas, também a situação familiar insustentável é a principal causa do desabrigo, mas com destaque para a violência doméstica. O lugar que se atribui à figura feminina na família está ligado à organização, construção e manutenção dos laços afetivos, à valorização do trabalho doméstico e a referências simbólicas ligadas à casa ${ }^{1}$. Nesta pesquisa, as duas mulheres entrevistadas ficavam na zona Sul da cidade, onde se encontram mais residências, diferentemente do Centro, onde prevalecem estabelecimentos comerciais.

Diante de tantas dificuldades para se sustentar no seio familiar, a rua surge como oportunidade de vida melhor ou, pelo menos, de se livrar de uma dor maior. A rua oferece certa liberdade, mesmo que relativa, levando o sujeito a se sentir dono de si, construindo seu espaço de moradia e vida ${ }^{2}$. As vulnerações ${ }^{11,12,20}$, no entanto, tornam a pessoa em situação de rua refém, principalmente quando o próprio indivíduo não as reconhece como tal. Nesse sentido, Anjos ${ }^{21}$ aponta que pessoas em situação de rua que reconhecem a vulnerabilidade a que estão submetidas têm mais autonomia na forma de pensar e agir, buscando transformar suas condições de vida. Nessa situação, paradoxalmente, vulnerabilidade e autonomia se tornam parceiras.

Na sociedade degradada econômica e socialmente, em razão do absolutismo individualista que descaracteriza o valor da cidadania nas relações pessoais, o desemprego é problema evidente ${ }^{6}$. A tecnologia avança a passos largos para substituir o ser humano na produção econômica, o que agrava ainda mais o quadro, principalmente para trabalhadores informais e menos qualificados ${ }^{6}$.

Assim, o desemprego tem levado muitas pessoas a viver na rua, modificando o perfil tradicional dessa população, caracterizado por pedintes, usuários de drogas e doentes mentais $^{6}$. Trata-se agora de pessoas que demonstram agir com a perspectiva de mudar de condição. No entanto, esse novo perfil também é atravessado pelas vulnerações ${ }^{11,12,20}$ impostas pela situação de rua, em condição de fragilidade na qual é difícil sustentar o cuidado de $\mathrm{si}^{22,23}$. Além disso, o afastamento da família gera angústia, tristeza e sentimento de incapacidade naquele que seria o provedor do lar.

As vulnerações dificultam a produção da subjetividade que permite ao sujeito se organizar e se relacionar consigo mesmo e com o outro ${ }^{24}$. Entretanto, a singularidade dos entrevistados nesta pesquisa se destacou de várias maneiras, como o local escolhido para viver e as pessoas com quem se agrupam para se proteger, as críticas às instituições de acolhimento e às políticas públicas e a decisão de se afastar da violência doméstica e ir para a rua. Contudo, percebe-se certa desqualificação do sujeito por si mesmo, uma descrença nas próprias capacidades que se reflete, por exemplo, no uso abusivo de bebidas alcoólicas, comprometendo perspectivas melhores de vida e a autonomia necessária para diminuir o efeito das vulnerações ${ }^{25}$.

De acordo com os entrevistados, a fome não é uma vulneração que os atinge especialmente, pois a alimentação é encontrada facilmente na rua (o que pode naturalizar a permanência ali). Escorel ${ }^{1}$, por exemplo, aponta a facilidade de conseguir alimento como uma das motivações para continuar na rua. 
No entanto, também se pode considerar a privação da escolha do que comer como uma vulneração.

A estigmatização também dificulta o avanço da pessoa em direção a outras perspectivas de vida. Acaba-se naturalizando a situação de rua, e o sujeito passa a não acreditar que é possível encontrar outros caminhos. Há indivíduos que estão na rua há mais de dez anos. A permanência leva a um processo de "rualização" ${ }^{26}$, configurado por múltiplas condições, que se intensifica com o tempo.

Essa estigmatização gera sofrimento, desqualifica o sujeito, mata a subjetividade e ignora as diferenças. A pessoa em situação de rua passa então a ser vista como ladra, malcheirosa, bêbada, vagabunda. O preconceito e a estigmatização criam marcas profundas nessas pessoas e na sociedade, velando as diferenças sociais, culturais e subjetivas próprias do ser humano. Nessas condições o enfrentamento se torna insustentável, levando à invisibilidade esse grupo específico ${ }^{27}$.

Morando na rua, as dificuldades para encontrar emprego são grandes, o que leva à autodepreciação e à necessidade de aceitar qualquer trabalho, ainda que mal remunerado, sem garantia de direitos trabalhistas e sem compromisso ético dos empregadores, que colocam em risco vidas pelas quais ninguém se responsabiliza. A desqualificação do profissional que vive nas ruas está ligada a fatores políticos e sociais que afetam esse grupo ${ }^{6}$.

Para as pessoas em situação de rua, o trabaIho regulamentado - formal ou não, com rotina e renda compatíveis e valorização devida de habilidades e competências - é a principal possibilidade de organizar e planejar uma vida futura. Aqueles que se sentem valorizados e reconhecidos por seu trabalho conseguem gerir melhor a vida e ganhar força na luta pelos direitos humanos. Como aponta Castel ${ }^{28}$, o sujeito se insere na sociedade por meio do trabalho.

Nessa ótica, estabelece-se relação dicotômica entre exclusão e inclusão: quem não trabalha é marginalizado, desvalorizado e sente mais dificuldades em suas relações sociais. Por isso é importante atentar para as vulnerabilidades resultantes da ausência de trabalho, que podem tornar crônica a situação de rua. Mesmo no convívio do grupo, as pessoas em situação de rua que desenvolvem um trabalho são menos discriminadas ${ }^{29}$.

As instituições de acolhimento das secretarias de assistência social oferecem abrigo a adultos em situação de rua. Seu objetivo é reinseri-los no âmbito familiar, ofertar cursos de capacitação para o trabaIho e garantir espaço de moradia digna. Contudo, nem sempre esses objetivos são conquistados. É responsabilidade dessas instituições públicas promover o cuidado integral a seus assistidos, levando em conta suas vulnerações ${ }^{30}$. Mas as pessoas em situação de rua recorrentemente apontam as condições sanitárias inadequadas desses espaços, quase sempre localizados longe dos grandes centros comerciais da cidade, dificultando a inserção dos abrigados no mercado de trabalho e afastando-os da convivência em sociedade.

O sujeito se transforma pela potência de estabelecer relações sociais, em que influencia e é influenciado pelo outro ${ }^{22,23}$. Percebe-se que os indivíduos em situação de rua têm dificuldade de questionar seus conflitos, suas inquietações. O trabalho coletivo em saúde se faz então importante, compartilhando o cuidado e amparando os excluídos, como preconizado pela bioética de proteção ${ }^{11-13}$.

Partindo da constatação de desigualdades entre cidadãos em uma mesma sociedade, a bioética de proteção surge como instrumento reflexivo e prático possível para amparar grupos vulnerados. Essa proposta visa enfrentar situações que privam os sujeitos da possibilidade de realizar seus projetos de vida. Dessa maneira, a bioética de proteção pode ajudar pessoas em situação de rua a vencer desafios, dando-lhes suporte, viabilizando dispositivos de acolhimento e implementando políticas públicas que desenvolvam potencialidades obscurecidas. O objetivo é que a pessoa acolhida um dia possa prescindir dessa proteção ${ }^{11-13}$.

O vínculo com pessoas e instituições de cuidado ajuda a empoderar indivíduos em situação de rua. Os profissionais, conhecendo as vulnerações que afetam esses indivíduos, por meio do cuidado ético proposto pela bioética de proteção ${ }^{11-13}$, podem auxiliá-los a se apropriar de sua autonomia, revertendo o caminho de desempoderamento a que estão sujeitos.

\section{Considerações finais}

Este estudo buscou dar voz a pessoas em situação de rua, invisibilizadas pela sociedade e pelo Estado, que lhes negam o sentimento de pertencer à cidade. As vozes aqui apresentadas devem ser ouvidas por profissionais que cuidam de pessoas em situação de rua, por aqueles que querem cuidar delas e pela sociedade (que tem dúvidas sobre como lidar com esse grupo) e sobretudo por criadores de políticas públicas, que têm compromisso ético e político com essa população. 
As vulnerações sofridas interferem nas escoIhas e no autocuidado da pessoa em situação de rua, impedindo a vida digna, com acesso aos direitos constitucionais ${ }^{31}$. Para esses sujeitos, planejar o futuro é muito difícil, e por vezes se "acostumam" a viver na rua, perdendo a autonomia para decidir sobre a própria vida. A aposta para sair dessa situação é o trabalho regulamentado com salário compatível, que só costuma ser ofertado, no entanto, para pessoas com domicílio.

A bioética da proteção ${ }^{11-13}$, a partir do compartilhamento de saberes, propõe amparar a pessoa em situação de rua por meio de dispositivos de cuidado que permitam acolher demandas, construir espaços coletivos e singulares de representação de direitos e implementar políticas públicas. Trata-se de proposta de cuidado viável para essa população vulnerada, que busca autonomia e direitos iguais, conforme $o$ princípio da equidade.

Esta pesquisa limitou-se a estudar a população em situação de rua que exerce algum tipo de trabalho. Acredita-se, porém, que os resultados aqui apresentados podem subsidiar políticas públicas voltadas a esta população como um todo.

\section{Referências}

1. Escorel S. Vidas ao léu: trajetórias da exclusão social. Rio de Janeiro: Fiocruz; 1999.

2. Andrade LP, Costa SL, Marquetti FC. A rua tem um imã, acho que é liberdade: potência, sofrimento e estratégias de vida entre moradores de rua na cidade de Santos, no litoral do estado de São Paulo. Saúde Soc [Internet]. 2014 [acesso 30 out 2020];23(4):1248-61. DOI: 10.1590/S0104-12902014000400011

3. Resende VM, Mendonça DG. População em situação de rua e políticas públicas: representações na Folha de São Paulo. Delta [Internet]. 2019 [acesso 30 out 2020];35(4):e2019350413. DOI: $10.1590 / 1678-460 \times 2019350413$

4. Brasil. Decreto no 7.053, de 23 de dezembro de 2009. Institui a Política Nacional para População em Situação de Rua e seu Comitê Intersetorial de Acompanhamento e Monitoramento, e dá outras providências. Diário Oficial da União [Internet]. Brasília, 24 dez 2009 [acesso 30 out 2020]. Disponível: https://bit.ly/2HAL2QR

5. Scott JB, Prola CA, Siqueira AC, Pereira CRR. O conceito de vulnerabilidade social no âmbito da psicologia no Brasil: uma revisão sistemática da literatura. Psicol Rev [Internet]. 2018 [acesso 30 out 2020];24(2):600-15. DOI: 10.5752/P.1678-9563.2018v24n2p600-615

6. Reis D. População em situação de rua e sua relação com o trabalho: as estratégias de sobrevivência utilizadas pelas pessoas em situação de rua [monografia] [Internet]. Florianópolis: Universidade Federal de Santa Catarina; 2012 [acesso 16 out 2019]. Disponível: https://bit.ly/32Ztoxl

7. Aumenta o número de pessoas em situação de rua no Brasil. EBC [Internet]. $11 \mathrm{dez} 2018$ [acesso 21 maio 2019]. Disponível: https://bit.ly/3kJIEWB

8. Número de pessoas em situação de rua aumenta mais de $150 \%$ em 3 anos no Rio. EBC [Internet]. 4 jun 2017 [acesso 21 maio 2019]. Disponível: https://bit.ly/3kMqyCi

9. Prefeitura do Rio de Janeiro. População de rua 2013: um direito à cidade [Internet]. Rio de Janeiro: Secretaria Municipal de Desenvolvimento Social; 2013 [acesso 21 maio 2019]. Disponível: https://bit.ly/3kNt7UL

10. Motta LCS, Vidal SV, Siqueira-Batista R. Bioética, afinal o que é isto? Rev Bras Clín Med [Internet]. 2012 [acesso 31 out 2020];10(5):431-9. Disponível: https://bit.ly/36QCHkH

11. Schramm FR. Bioética da proteção: ferramenta válida para enfrentar problemas morais na era da globalização. Rev. Bioética [Internet]. 2008 [acesso 26 maio 2019];16(1):11-23. Disponível: https:// bit.ly/390607c

12. Schramm FR. A bioética de proteção: uma ferramenta para a avaliação das práticas sanitárias? Ciênc Saúde Coletiva [Internet]. 2017 [acesso 28 maio 2019];22(5):1531-8. DOI: 10.1590/1413-81232017225.04532017

13. Schramm FR. A bioética dos vulnerados (entrevista ao Centro de Bioética do Cremesp) [Internet]. São Paulo: Centro de Bioética do Cremesp; 2009 [acesso 6 maio 2019]. Disponível: https://bit.ly/3fru97X

14. Instituto Brasileiro de Geografia e Estatística. Censo 2010 [Internet]. Rio de Janeiro: IBGE; 2018 [acesso 27 maio 2019]. Disponível: https://bit.ly/2Uldmno

15. Prefeitura do Rio de Janeiro. Plano Municipal de Saúde do Rio de Janeiro: 2014-2017 [Internet]. Rio de Janeiro: Secretaria Municipal de Saúde; 2013 [acesso 23 maio 2019]. Disponível: https://bit.ly/36NNKeA

16. Brasil. Ministério da Saúde. Portaria no 2.436, de 21 de setembro de 2017. Aprova a Política Nacional de Atenção Básica, estabelecendo a revisão de diretrizes para a organização da atenção básica, no âmbito do Sistema Único de Saúde (SUS). Diário Oficial da União [Internet]. Brasília, 22 set 2017 [acesso 26 nov 2020]. Disponível: https://bit.ly/366aOpw

17. Brasil. Ministério da Saúde. Portaria no 122, de 25 de janeiro de 2011. Define as diretrizes de organização e funcionamento das Equipes de Consultório na Rua. Diário Oficial da União [Internet]. Brasília, 26 jan 2012 [acesso 25 maio 2019]. Disponível: https://bit.ly/376ewiv 
18. Prefeitura do Rio de Janeiro. Diretrizes norteadoras das equipes do consultório na rua do município do Rio de Janeiro. Rio de Janeiro: Secretaria Municipal de Saúde; 2017.

19. Brasil. Orientações técnicas: centro de referência especializado de assistência social (Creas) [Internet]. Brasília: Ministério do Desenvolvimento Social e Combate à Fome; 2011 [acesso 25 maio 2019]. Disponível: https://bit.ly/2UFoK3t

20. Sotero M. Vulnerabilidade e vulneração: população de rua, uma questão ética. Rev. bioét. (Impr.) [Internet]. 2011 [acesso 25 maio 2019];19(3):799-817. Disponível: https://bit.ly/332kT57

21. Anjos MF. A vulnerabilidade como parceira da autonomia. Rev Bras Bioét [Internet]. 2006 [acesso 18 maio 2019];2(2):173-86. Disponível: https://bit.ly/36ViuKs

22. Foucault M. História da sexualidade III: o cuidado de si. Rio de Janeiro: Graal; 2009.

23. Foucault M. História da sexualidade II: o uso dos prazeres. Rio de Janeiro: Graal; 1990.

24. Guattari F, Rolnik S. Micropolítica: cartografias do desejo. 4a ed. Petrópolis: Vozes; 1996.

25. Medeiros RP. Entre as andanças e as travessias nas ruas da cidade: territórios e uso de drogas pelos moradores de rua. Civitas [Internet]. 2019 [acesso 23 out 2020];19(1):142-58. DOI: 10.15448/1984-7289.2019.1.30759

26. Prates JC, Prates FC, Machado S. Populações em situação de rua: os processos de exclusão e inclusão precária vivenciados por este segmento. Temporalis [Internet]. 2011 [acesso 19 maio 2019];11(22):191-215. Disponível: https://bit.ly/36V6MQh

27. Mattos RM, Ferreira RF. Quem vocês pensam que (elas) são? Representações sobre as pessoas em situação de rua. Psicol Soc [Internet]. 2004 [acesso 17 maio 2019];16(2):47-58. Disponível: https://bit.ly/2UJbpak

28. Castel R. A dinâmica dos processos de marginalização: da vulnerabilidade à "desfiliação". Cad CRH [Internet]. 1997 [acesso 16 maio 2019];10(26):19-40. DOI: 10.9771/ccrh.v10i26.18664

29. Varanda W, Adorno RCF. Descartáveis urbanos: discutindo a complexidade da população de rua e o desafio para políticas de saúde. Saúde Soc [Internet]. 2004 [acesso 12 maio 2019];13(1):56-69. DOI: 10.1590/S0104-12902004000100007

30. Brasil. Política Nacional de Assistência Social: PNAS/2004 [Internet]. Brasília: Ministério do Desenvolvimento Social e Combate à Fome; 2004 [acesso 25 maio 2019]. Disponível: https://bit.ly/2IVoQB7

31. Brasil. Constituição da República Federativa do Brasil de 1988. Diário Oficial da União [Internet]. Brasília, 5 out 1988 [acesso 1o nov 2020]. Disponível: https://bit.ly/35LHN2p

\section{Participação das autoras}

Jane da Rocha Cruz idealizou o estudo e coletou os dados. Stella Regina Taquette orientou a pesquisa e revisou o artigo. Ambas as autoras analisaram os dados e redigiram o manuscrito.

\section{Correspondência}

Jane da Rocha Cruz - Rua Tenreiro Aranha, s/n, Copacabana CEP 22031-090. Rio de Janeiro/RJ, Brasil.

Jane da Rocha Cruz - Mestre - cruzjanerocha@gmail.com

(iD) 0000-0002-6768-5302

Stella Regina Taquette - Doutora - stella.taquette@gmail.com

(iD) $0000-0001-7388-3025$ 